\title{
Innovation In Business Education: Developing A High Quality Online MBA
}

C. William Roe, Arkansas State University, USA

Alfred G. Toma, Unversity of Louisiana, Lafayette, USA

RamMohan R. Yallapragada, Fayetteville State University, USA

\begin{abstract}
Online degree programs were probably pioneered by for-profit universities such as University of Phoenix. Many online degree programs were initially considered low quality academic programs compared to traditional programs. Therefore, many public and private universities were slow to adopt the online programs. However, gradually more and more "non-traditional" students began to enter schools. Employees already holding jobs began to seek to better their qualifications by coming back to school while still working. For both these groups, online degree programs offered an opportunity to go to school while still employed. Consequently, many schools offering traditional MBA programs are forced to offer online MBA programs to meet the demand and to beat the competing schools. In keeping up with the trend, Arkansas State University launched a high quality online MBA program that parallels the best of the ongoing online MBA programs. This MBA program has been ranked number 1 in faculty credentials and training and in the top 15 in all categories among all online MBA programs by U.S. News and World Report for three consecutive years. This paper presents how the Graduate Faculty of Arkansas State's College of Business developed its high quality online MBA and how the program operates with revenue sharing for the College of Business.
\end{abstract}

Keywords: Online MBA Degree Programs; Non-Traditional; High Quality; U. S. News \& World Report; Number One; Top Fifteen

\section{INTRODUCTION}

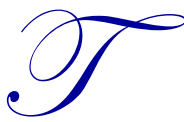

he industrial revolution in the $19^{\text {th }}$ century wrought a lot of sweeping changes in the workforce in the United States (US) economy. Most of the manual labor in all industries was replaced by machines. There was a need for the workforce in the production environment to have more and more business and management skills, instead of just putting in physical labor. The urgent need for these skills had a direct impact on the educational world and the Master of Business Administration (MBA) was born (www.ehow.com). According to Gupta and Saunders (2007), the MBA degree originated in the U.S. in the last quarter of the $19^{\text {th }}$ century. As a direct result of rapid industrialization of the country, companies began to search for scientific methods toward management of business organizations. In academic terms, the advent of the MBA has been a phenomenal success in the US.

The world's first collegiate school of business was initiated in 1881 by Joseph Wharton, a prominent steel industrialist in Philadelphia, when he donated $\$ 100,000$ to the University of Pennsylvania to found the Wharton School of Finance and Economy, which was later renamed as Wharton School of Finance and Commerce. The progress of business education in the US was at first very slow. It was not until 1898 that the second and third schools of business education in America were started by the University of Chicago and the University of California, Berkeley, respectively (Wren and Van Fleet, 2005). 


\section{Timeline Of MBA Schools}

1881: The first school of business education in the world was the Wharton School of Finance and Commerce established in 1881.

1898: The next schools of business education were established at the University of Chicago and the University of California-Berkeley, both in 1898.

1990: The first graduate school of business, the Tuck School of Business, was founded at Dartmouth in 1900. It was considered a very bold move at that time. Tuck was the very first school in the world to confer a master degree in commercial sciences, a Master of Science in Commerce, which became a forerunner of the present MBA (www.tuck.dartmouth.edu).

1908: One of the most reputable graduate business programs in the world, the Harvard MBA, was established at Harvard University in 1908. It was the very first business education program in the world to confer a degree to be called an MBA. The first year curriculum was based on Frederick Taylor's epic, "Scientific Management" (www.hbs.edu).

1924: The world-famous "Case Method" in business education was initiated in the Harvard MBA Program in 1924.

1930: The Massachusetts Institute of Technology (MIT) Sloan Fellows Program, introduced in 1930, was the first management/leadership education program to be created for mid-career, experienced managers.

1943: In 1943, The University of Chicago Booth School of Business began to offer the EXECUTIVE MBA (EMBA) Program for employed, working professionals, the first of such MBA programs to be offered anywhere. Now, many schools offer an EMBA.

1986: In 1986, the Roy E. Crummer Graduate School of Business at Rollins College, Florida became the first MBA school to require every student to have a laptop computer in the classroom.

\section{MBA Program At Arkansas State University}

\section{Traditional MBA}

Arkansas State University was established in Jonesboro, Arkansas in 1910 as the state's first Agricultural School, and then by 1932 it evolved into a four-year degree college. Graduate programs at the master level began to be offered in 1955 and the institution came to be known as Arkansas State University (ASU) in 1967. The MBA program was started at ASU in 1972 as a traditional, two-year, professional degree program designed to prepare students of all educational and professional backgrounds for management positions in all types of organizations. Courses were first offered on campus in late afternoons and evenings, then at three distance sites and, most recently, online.

\section{Online MBA Program At ASU}

Online degree programs are certainly not new, but in fact have been around for a number of years and may have largely been pioneered by for-profit universities, such as University of Phoenix. In many instances, online degree programs have suffered from the stigma of being low quality academic programs and lacking the rigor of traditional face-to-face programs. Thus, primarily for this reason, typical brick and mortar public and private universities were slow to enter the online arena. However, the changing profile of college degree seekers provided a huge market demand for the online delivery format as more and more "non-traditional" students either started college or re-entered college after having dropped out for various reasons and found themselves trying to balance careers and family responsibilities while attending classes. In addition, increasing costs of college education have forced larger numbers of traditional students to work in order to help pay for their education. For both these groups 
online degree programs seemed to be the answer, providing the flexibility to work on getting a degree and being able to work at a job as well. In this environment, providers of online degree programs expanded into virtually every state taking market share from traditional brick and mortar institutions, and forcing them also to offer online programs in order to compete. It is against this backdrop under which the administration of Arkansas State University mandated that the College of Business develop and offer an online MBA. The result of this has been the launching of a high quality online MBA that parallels the f2f MBA and stresses the importance of student-tostudent, student-to-faculty and faculty-to-student interaction and engagement in a completely online program. The program specifically includes online proctoring of exams through the use of a remote proctoring camera. This MBA program has been recognized for its quality by being ranked number one in faculty credentials and training, and in the top 15 in all categories among all AACSB accredited online MBA programs by U. S. News and World Report in each of the three years, which U. S. News has ranked online MBA programs.

The ASU Online MBA is considered by many as being ideal for ambitious, working professionals interested in a superior MBA program which is more flexible with working schedules than a traditional MBA program. The following sections present how the Graduate Faculty of Arkansas State's College of Business developed its high quality online MBA and how the program operates with revenue sharing for the College of Business.

\section{Development Of A High-Quality Online MBA Program At ASU}

The charge from the Provost of the University was simply to develop an online MBA program that would allow the College of Business to compete with other in-state online MBA degree providers in the dramatically changing landscape of higher education. In undertaking this charge it was the decision of the Associate Dean, the Director of Graduate Business Programs, and the Graduate Programs Committee (GPC) to develop a high quality online MBA that would parallel the traditional MBA, allow the $\mathrm{CoB}$ to continue to deliver its MBA program to 3 distance site campuses, as well as to allow "migratory" managers, who had begun an MBA at ASU, to complete their degree. It would also allow completion opportunities for current students who relocated prior to completion of their degree, to target concentrations of alumni to pursue an MBA from their alma mater, and to eventually expand the program throughout the US as approved by various higher education boards of states.

\section{Initial Strategies}

Before undertaking the development of a high-quality online MBA, it was decided by the GPC to benchmark best practices of existing online MBA programs. To accomplish this, the GPC selected two distinctly different programs - one offered by Penn State University and one at East Carolina State University. The former being a relatively high-cost, lower enrollment model and the latter a relatively low-cost, higher enrollment model. Staff from the program at Penn State came to ASU to meet with members of the GPC while a conference call was held between the GPC and staff from ECSU's MBA program, to discuss a number of different issues including program development, tuition, admission requirements, course loads/class size, testing, faculty workloads, student engagement, synchronous/asynchronous delivery, and other issues relevant to high quality in the online delivery format.

Based upon information gathered from the meetings with PSU and ECSU, the GPC worked with members of the Graduate Faculty, the Executive Committee and the Planning Committee of the $\mathrm{CoB}$ to reach other strategic decisions regarding the development and delivery of ASU's online MBA. 


\section{Implementation Strategies}

Several strategies were decided upon by the GPC, the Graduate Faculty, the Planning Committee, and the Executive Committee, all aimed at helping to ensure that ASU's online MBA was of the highest quality possible as well as come as close as possible to mimicking the traditional, or f2f, MBA. These strategies were as follows:

- $\quad$ Content Standards - The online MBA would consist of the same courses and the same material within these courses as the f2f MBA.

- $\quad$ Parallel Delivery - The online MBA courses would be offered on a rotation basis, and each time a course would be offered, the same course would be taught f2f.

- $\quad$ Online Teaching Faculty - The same faculty teaching a course online would also teach the same course during the same semester f2 $\mathrm{f}$ to help ensure that there was consistency in course content across both delivery formats, and that the online students were, in fact, getting the same educational experience as f2f students were getting.

- $\quad$ Faculty Credentials and Training - Only faculty who met the criteria for appointment to the Graduate Faculty would be allowed to teach in both the $\mathrm{f} 2 \mathrm{f}$ and online delivery modes. This assured that faculty met Standard 15 of AACSB's newly adopted criteria for eligibility, that being Scholarly Academics (formerly AQ faculty). Further, it was decided that only full-time Graduate Faculty would be allowed to teach in both delivery formats simultaneously, that no part-time faculty or no faculty contracted outside of ASU's $\mathrm{CoB}$ would be allowed to teach these courses. Also, the Executive Committee decided to allocate faculty development funds to provide training in online delivery through the University's Interactive Teaching and Technology Faculty Center (ITTC) before any faculty member would be allowed to teach the online courses to help ensure that faculty were applying effective online teaching and learning pedagogy.

- Branding-Again, using faculty development funds, the CoB contracted with ITTC to develop a common shell for each online MBA course to create the same look, touch, feel, and functionality across all courses to not only create a consistent brand and image for each course, but to also help ensure that students could find the same information for each course in the same location to enhance navigation on $\mathrm{Bb}$ Learn, and to make each course more user friendly.

- Asynchronous Delivery-The GPC decided at the outset that the online program would be asynchronous, and that graduate faculty would either do Tegrity recordings of lectures or have ITTC record lectures either in the live classroom or in the ITTC production studio and upload these lectures to $\mathrm{Bb}$ so online. Students would not only receive the same information that f $2 \mathrm{f}$ students received, but that online students would be able to view these lectures at a time that did not interfere with work schedules or other time constraints.

- Student-Faculty and Student-Student Interactions-Standard 10 of the AACSB Standards states that "Curricula facilitate student-student and student-faculty interaction appropriate to the program type and achievement of learning goals." Essentially what this means is that students receiving instruction in any delivery mode, including online delivery, have the same opportunity for interaction with faculty and with students as do those in f $2 \mathrm{f}$ classes. To achieve this, the GPC provides guidance for every faculty member teaching online courses to have online discussions, chat boards and other appropriate interaction between students and faculty. Courses are designed to engage students to achieve teamwork and collaborative learning using such approaches as simulations and team projects. In such situations, teams are formed comprised of f2f and online students to help ensure a high level of student-student interaction. Where presentations are a part of the team projects online students participate in class in these presentations through $\mathrm{Bb}$ Collaborate or Google Talks, each one allowing the online student to be visually present in class, make a presentation and answer questions. Online students can both see and be seen using these technologies. This approach helps to ensure student engagement and complies with AACSB's Standard 13, which states "Curricula facilitate student academic and professional engagement appropriate to the degree program type and learning goals."

Two quotes from recent online students who graduated Summer 2014 serve to illustrate the importance of such interaction and engagement. One online student stated "Dr. Jones you are an excellent professor. I really enjoyed your videos, and the discussion questions which allowed us to interact and to see how our peers view certain ethical dilemmas, and things from different perspectives. Also, this class is great because you have allowed us to see how technology has changed and how beneficial it is when used 
properly. I would not change a thing about the course." Another online student wrote, "Dr. Roe thank you for the great experience we had in working on such a meaningful project in your class and for allowing the online students to work with f2f students on these projects. Every member of our team did their part, and we were able to work together and collaborate just as though we were all sitting in the classroom. It was a great experience to be able to be 'present' for the presentation, to see my teammates and our client and to be able to participate in the question and answer session. Thank you for such an awesome course and a great learning experience. I am glad I chose ASU for my online MBA.” In addition, emails received from two project clients illustrate how important it is to engage students professionally and academically. One client stated "Wow-I am beyond overwhelmed with the wonderful information I have for the pet hotel!!! I am amazed at the great work the group did, working together in a team of online and in class students, in such a short time. We absolutely intend to move forward with the business, and we have already started making contacts in commercial real estate to hopefully secure land very soon." And another client stated, "Thank you for putting a team of MBA students together to develop a strategic plan for our company. What has been accomplished in such a short period of time was beyond our expectations. The strengths and weaknesses of our company, which the team identified, were right on target and the recommendations for moving our company forward are exactly what we needed. For us this was a wake-up call and a new beginning."

- $\quad$ Class Size-Another important strategy in offering a high-quality online MBA deals with the size of the online class. It is well known by all who teach or have taught in the online delivery format, that it is much more time consuming, and requires much more intense interaction and connection with online students than with those in a traditional classroom sitting, if it is going to be done with emphasis on interaction, engagement and quality. Many universities have mass enrollment in online classes, which often result in hiring what is referred to as Academic Coaches, who read assignments, grade tests, and answer questions for students. Such large classes no doubt make it virtually impossible to have interaction and engagement of any type, and may often result in a reduction in quality of learning and the overall educational experience. Orellana (2006) conducted one of the most comprehensive studies to date on class size and concluded that the optimal online class size is 19 students. Knowing that the administration of the university would not agree with class limits of that number, the GPC opted to cap online classes at 30 students each.

- $\quad$ Pricing Strategies and Revenue Sharing-The GPC determined at the outset that the online MBA would be priced higher than the traditional MBA. In attempting to determine how the program would be positioned price-wise with other programs, extensive research was conducted to see how other AACSB accredited programs were priced across all sizes and tiers of business schools. Research revealed a wide range of pricing online MBA programs from a low of approximately $\$ 6,500$ to a high of $\$ 65,000$. The GPC did not want to be at the bottom end of the range, but also was cognizant of not pricing so high as to not be competitive. It was decided to set a price at the $20^{\text {th }}$ percentile of the price range of online MBA programs initially, and to gradually increase the price in relatively small increments over time, to maintain somewhat of a "premium price" for the online MBA over the traditional MBA. Once this price was determined the GPC negotiated a revenue sharing agreement with the administration of the university, whereby the CoB would keep $80 \%$ of the online tuition revenue over and above the tuition of the traditional MBA. In three years this has generated over $\$ 350,000$ for the College of Business.

\section{Piloting And Official Launch Of The Program}

The GPC made a conscious decision to pilot the program for one year by making it available only to the students who were enrolled in the MBA program at two sister campuses, and one degree center, all in Arkansas. The purpose of limiting enrollment to these students was to allow faculty to gain experience in online teaching before making the program available to a broad market and to obtain feedback from students to work out any "bugs" and to fine tune the program. After one year of piloting the program, the $\mathrm{CoB}$ officially launched the program nationwide to all states in which Arkansas State University had obtained approval to offer the degree. To date, the delivery of the online program is approved in 36 states and students are enrolled in the program across all these states.

Peer Review For Continuous Improvement 
It is well known that Maintenance of AACSB Accreditation has as its cornerstone continuous improvement in all processes. In fact, the Maintenance Review has been changed so it is now called the Continuous Improvement Review. In this spirit of continuous improvement to help ensure that ASU's online MBA program becomes even better over time, the GPC established a peer review process at the time the program was officially launched. Under this peer review process, each member of the GPC is assigned to an online course each semester for the purpose of reviewing the online faculty member's online teaching techniques and processes, but in no way to review the course material that is being taught. The GPC wants to ensure that faculty are engaging students, and that there is a high degree of student-student and student-faculty interaction and that there is collaboration among all students, and the peer review process involves looking at how these are being accomplished and what types of unique approaches are being used by faculty to do so. The GPC member is entered in the course on Bb just as any other student might be, and the review involves providing constructive feedback and/or positive reinforcement to the professor. At no time is information from the peer review shared with the faculty member's department chair, or with other faculty, unless the faculty member has some best practices which could be helpful for other faculty to be aware of and consider adopting for their own courses. This approach has proved to be very beneficial in enhancing the quality of the online experience for students enrolled in the program.

Pervasive Problem Of Academic Dishonesty Among Students In The U.S.

As Brown et al. (2010) report, student academic dishonesty/cheating has been recognized as a serious problem in U. S. colleges and universities for many years. The percentage of students admitting to cheating has become alarming, ranging from about 49\% among undergraduate marketing majors in 1988 to $100 \%$ of undergraduate management majors in 2008 in the U. S. According to Keith-Spiegel et al. (1998), one possible reason that many faculty members tend to ignore cheating is that administrators, especially deans, have not given high priority to the problem. Teixeira et al. (2010) found that students enrolled in universities in the Western countries reveal statistically significant high propensities towards committing academic fraud. Kolker (2012) described several high-profile recent cases of cheating among students at world-famous schools such as Stuyvesant High School in New York City and the famous Harvard University in Cambridge, Massachusetts. The cheating scandal at Harvard University received world-wide attention and involved about 125 students out of a total of 279 enrolled in a government course (Webley, 2012).

\section{Test Integrity And Test Taker Authentication}

The GPC at ASU pays special attention to this pervasive problem of academic cheating and plans to nip it in the bud itself. To deal with academic dishonesty, and to maintain the integrity of online tests, as well as the online program, and to authenticate test takers, the GPC requires each student to purchase or lease the SecureCam Remote Proctor Camera. The student must register the camera with their photo ID, and their thumbprint in order to be able to $\log$ on to the camera, and must do so each time they take a test. The camera takes a 360 degree video of the test taker and the test taker's surroundings, and these videos are viewed by SecureCam personnel who red circle any frame which looks like it could be an act of academic dishonesty, and forwards any such frames to the professor to determine if cheating has occurred, or if there is the appearance of academic dishonesty on the test. This system has worked very well, and just the mere fact that students know they are being video-taped appears to be having a dampening effect on any attempts to cheat.

\section{Handbook and Resource Directory}

To provide guidance to online teaching faculty, and to provide a resource for newly hired faculty, the GPC developed an Online Handbook and Resource Directory which is provided each faculty member teaching online courses. The GPC worked with members of the Graduate Faculty in developing this important resource which serves as a guide for all faculty, addressing all policies, procedures, tools and resources available to the faculty, and supports initiatives for quality, consistency and continuous improvement. 


\section{CONCLUSION}

The Graduate Program Committee in the College of Business sets out to develop an online MBA program as a mandate from the administration of Arkansas State University. It is well documented that many employers have negative perceptions about the quality of online higher education degrees, and that there is a general public perception that online degree programs lack rigor and quality. Hunt (2013) states that while online education is convenient for many students and is also cost-effective for many cash-strapped schools; there are many critics who are concerned about the overall quality of a degree earned solely through an electronic delivery system. Recently, a literature review was conducted which explored extensive research regarding the perception of potential employers about online degrees as compared with degrees earned through the traditional format (Columbaro and Monaghan, 2009). The review revealed that there still is a marked stigma attached to online degrees and that employers overall have a negative perception about online degrees. In fact, many students, themselves, perceive that online degree programs are of low quality and do not challenge them to learn. The most frequently asked question of those who are inquiring about ASU's online MBA is "Will my diploma say Online Master of Business Administration or just Master of Business Administration." This indicates that they, too, know the poor image that online degree programs can have among potential employers and the public at large. The goal of the GPC was, and still is, to develop and deliver the highest quality online MBA possible. Each strategy employed by the GPC and the Graduate Faculty has resulted in a high-quality online MBA which has been ranked by U. S. News and World Report for three consecutive years as number one in Faculty Credentials and Training and is in the top 15 of all online MBA programs among all categories of information collected by U. S. News. In addition, the ASU online MBA is the only top ranked online MBA ranked in the top 10 high-quality affordable online MBA programs for two consecutive years (http://www.top10onlinecolleges.org/affordable-online-business-graduate-degrees/ ) .

\section{AUTHOR INFORMATION}

RamMohan R. Yallapragada, Ph.D., is a Professor of Accounting at Fayetteville State University. He obtained his $\mathrm{PhD}$ degree in Accounting from the University of Houston. He holds a CPA certificate from the State of Louisiana. His research areas include cost accounting in healthcare, accounting irregularities in Fannie Mae, impact of Sarbanes-Oxley Act of 2002 on American corporations, and issues involved in incorporation of IFRS in the United States. E-mail: ryallapr@uncfsu.edu (Corresponding author).

C. William Roe, Ph.D., received his doctorate from Mississippi State University in Management. He has published numerous journal articles in management, marketing, healthcare administration, and international business. He currently serves as Associate Dean and Director of Graduate Business Programs at Arkansas State University. He has consulted extensively with numerous public, private, for-profit, and not-for-profit organizations in the areas of strategic planning, leadership, organizational change and development, and management development. E-mail: broe@astate.edu.

Alfred G. Toma, Ph.D., is an Assistant Dean of Administration at the University of Louisiana, Lafayette. He holds the degrees of M.B.A. from the American University of Beirut, Lebanon and M.Sc in Marketing from Louisiana State University. He has published several journal articles and conference papers in the areas of international business and entrepreneurship. He currently teaches courses in international business management, entrepreneurship, and human resources management at the University of Louisiana at Lafayette. His extensive actual business and consultancy experiences are focused on the areas of entry and operations in Middle East markets and entrepreneurial ventures start-ups. E-mail: agt5159@louisiana.edu.

\section{REFERENCES}

Brown, B.S., Weible ,R.J. and Olmosk, K.E (2010). "Business School Deans on Student Academic Dishonesty: A Survey," College Student Journal, June 2010, Vol. 44, Issue 2, pp. 299-308.

Columbaro, N. L., \& Monaghan, C. H. (2009). Employer perceptions of online degrees: A literature review. Online Journal of Distance Learning Administration, 12(1). Retrieved from http://www.westga.edu/ distance/ojdla/spring121/columbaro121.html

Gupta, P.B., and Saunders, P.M., (2007), "Traditional Master of Business Administration (MBA) Versus the MBA 
With Specialization: A Dimension Between What Business Schools Offer and What Employers Seek," Journal of Business Education, July/August, 2007, Pp. 307-311.

History-About Us-Harvard Business School (http://www.hbs.edu/about/history.html)

Hunt III, A.W. (2013). "Cyber Schooling: On Internet Universities and Flesh-And-Blood Teachers," Touchstone, July/August 2013, pp. 17-19.

Keith-Spiegel, P., Tabchnik, B. E., Washburn, J., and Washburnm J. (1998). "Why Professors Ignore Cheating: Opinions of a National Sample of Psychology Instructors," Ethics and Behavior, Vol. 8, Issue 3, pp. 215227.

Kolker, R. (2012). “Cheating Upwards,” New York, 9/24/2012, Vol.45, Issue 30, pp. 34-99.

Orellana, A. (2006). "Class Size and Interaction in Online Courses," The Quarterly Review of Distance Education, Vol.7(3), 2006, pp.229-248.

Teixeira, A. and Rocha, M. (2010). "Cheating by Economics and Business Undergraduate Students: An Exploratory International Assessment," Higher Education, June 2010, Vol. 59, Issue 6, pp. 663-701

Tuck School of Business 1 History (http://www.tuck.dartmouth.edu/about/history/)

Webley, K. (2012). “Cheating Harvard,” Time, 9/17/2012, Vol. 180, Issue 12, p.22.

Wren, D.A. and Van Fleet, D.D. (2005). "History in Schools of Business," Academy of Management, Learning and Education, Vol. 4, Issue 1, 2005, pp. 44-56. 